\title{
The hidden structure in coral reefs
}

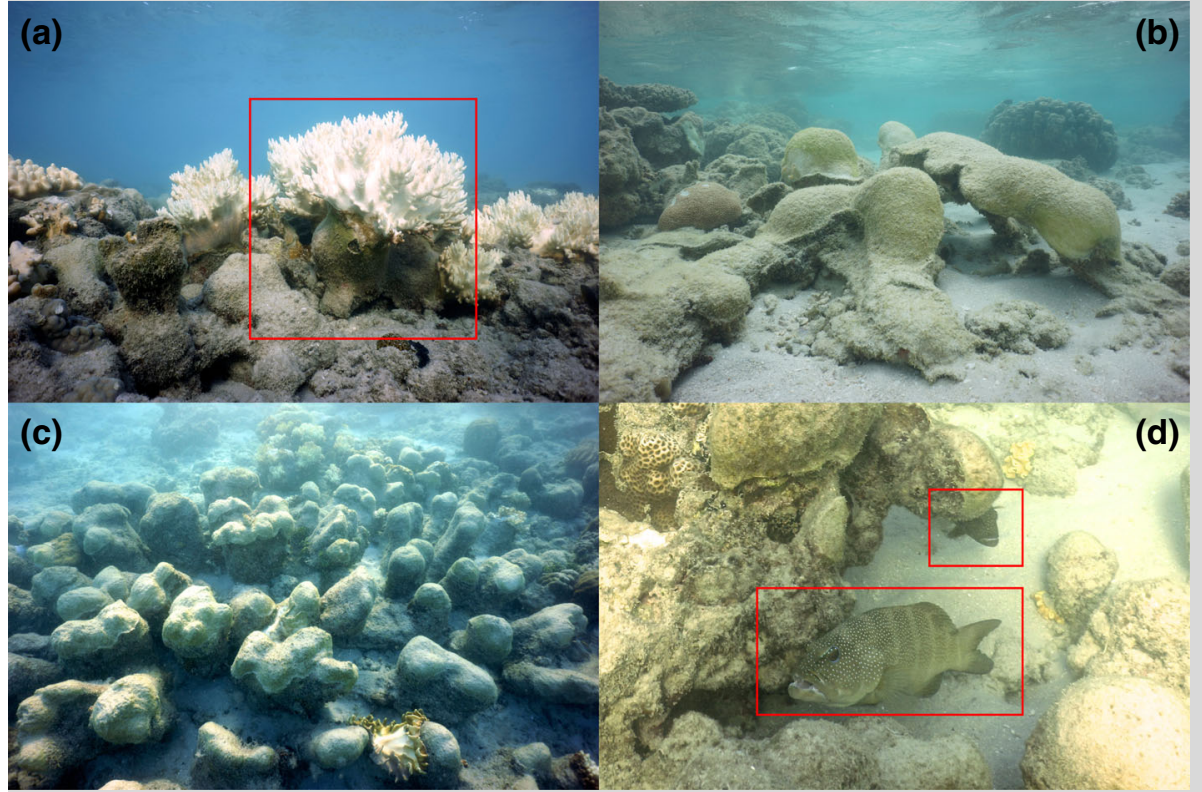

Fig. 1 a Bleached soft coral (Sinularia sp.) on Lizard Island reef flat. Note the large base of spiculite and calcium carbonate. b, c Complex habitat structure provided by recently dead soft corals. $\mathbf{d}$ Coral trout using the habitat structure provided by soft coral skeletons
Habitat structure is a key attribute of coral reef resilience. In 2016 coral reefs worldwide were struck by the most severe bleaching event recorded in history. We conducted post-bleaching surveys on the Great Barrier Reef and noted that as soft corals died, their hard skeletons were exposed, revealing intricate structures normally covered by live tissue. While snorkeling on a front reef at Lizard Island in June 2016, the importance of the structure provided by the soft corals' skeletons became apparent, as fish used these structures as refugia. Habitat structure provided by soft corals is often overlooked. However, calcifying soft corals of the genus Sinularia have been suggested as reef builders (Jeng et al. 2011).

We inspected live soft corals and found they provided a canopy that can cover complex structures made of spiculite and carbonate calcium, which in many cases provided greater habitat structure than hard corals of simple morphology. The soft corals we inspected often had skeletons taller than $50 \mathrm{~cm}$, an attribute related to high fish diversity and abundance (Harborne et al. 2012). We observed fish using the structure provided by both dead and living soft corals. Interestingly, Syms and Jones (2001) experimentally removed soft coral tissue from soft coral-dominated reefs and found no direct effect on fish assemblages. They hypothesized that fish assemblages were influenced by the underlying structure of soft coral skeletons, rather than the live animal. Our observations of fish using soft coral skeletons as shelter, even when the live corals were bleached or dead, support this hypothesis (Fig. 1).

Some reefs can have high densities of soft coral (Jeng et al. 2011). Therefore, studies of habitat structure on coral reefs should consider both hard and soft coral-dominated reefs to advance knowledge of coral reef ecology and understanding of how bleaching may impact the structure provided by soft corals and its relationship with fish assemblages.

\section{References}

Harborne AR, Mumby PJ, Ferrari R (2012) The effectiveness of different meso-scale rugosity metrics for predicting intra-habitat variation in coral-reef fish assemblages. Environ Biol Fishes 94:431-442

Jeng MS, Huang HD, Dai CF, Hsiao YC, Benayahu Y (2011) Sclerite calcification and reef-building in the fleshy octocoral genus Sinularia (Octocorallia: Alcyonacea). Coral Reefs 30:925-933

Syms C, Jones GP (2001) Soft corals exert no direct effects on coral reef fish assemblages. Oecologia 127:560-571

R. Ferrari (iD $(\bowtie)$

School of Life and Environmental Sciences, The University of Sydney, Science Road, NSW 2006, Australia

e-mail: renata.ferrari@sydney.edu.au

Received: 7 September 2016/Accepted: 3 January 2017/Published online: 9 January 2017

Coral Reefs (2017) 36:445

(C) Springer-Verlag Berlin Heidelberg 2017 DOI $10.1007 / \mathrm{s} 00338-017-1540-6$ 